\title{
Successful Cross-Campus Management of First Year Engineering Courses
}

\author{
Mark Steedman, Ken Smith, Patrick Keleher, Fae Martin \\ Faculty of Sciences, Engineering and Health \\ Central Queensland University, Australia \\ m.steedman@cqu.edu.au,k.e.smith@cqu.edu.au,p.keleher@cqu.edu.au,f.martin@cqu.edu.au
}

The first year of the CQU engineering undergraduate program

Abstract - Central Queensland University (CQU) is a young multi-campus regional university based in Rockhampton, Central Queensland, Australia. The engineering undergraduate program consists of a combination of Project-based Learning, cooperative education and professional practice. The first year of the engineering undergraduate program at $C Q U$ can be studied at any one of three campuses; Rockhampton, Gladstone or Mackay. Gladstone and Mackay campuses are separated by one hour and three hours travel by road respectively from the Rockhampton campus. During their first year of study, students have the opportunity to reside in their home city or region enabling a smoother transition from secondary to tertiary education. A significant component of the first year program is delivered using the Project Based Learning (PBL) paradigm, utilising a range of delivery modes including face-to-face workshops, synchronous video-conferencing of lectures, print-based materials, and web-based learning management.

In this paper, the authors examine the challenges associated with providing equitable learning opportunities for students studying first year PBL courses across the three campuses, and methods used to assess this. The advantages and disadvantages of modern electronic communication are considered, both from the point of view of staff and students. The additional complexity introduced when delivering a PBL course across remote campuses is also discussed.

Index Terms - cross-campus management, Project Based Learning, video-conferencing

\section{BACKGROUND}

At Central Queensland University (CQU) in Queensland, Australia, Rockhampton campus is the central hub of university operations, with teaching at several regional satellite campuses facilitated by local staff and on-line delivery and communication technologies. CQU has a strong focus on flexible teaching and learning that contributes to the sustainable development of the regions and communities in which it operates. consists of two teaching terms, each containing three courses, as shown in Table I.

TABLE I: CQU first year undergraduate engineering program

\begin{tabular}{|c|c|}
\hline Term 1 Courses & Term 2 Courses \\
\hline Engineering Skills I & Engineering Skills II \\
(12 credits) PBL & ( 12 credits) PBL \\
\hline Engineering Foundation Mathematics & Engineering Mathematics \\
( 6 credits) & $(6$ credits) \\
\hline Physics $1 \mathrm{~A}$ & $\begin{array}{c}\text { Physics } 1 \mathrm{~B} \\
(6 \text { credits })\end{array}$ \\
\hline
\end{tabular}

The CQU professional engineering undergraduate program is a combination of Project Based Learning (PBL), cooperative education and professional practice. The first year of the engineering undergraduate program can be studied at any one of three campuses; Rockhampton, Gladstone or Mackay. These campuses are separated by one hour and three hours travel by road respectively from the Rockhampton campus. This separation distance is significant enough to make regular face-to-face contact for all staff and students prohibitive in terms of travel/accommodation costs alone. The combination of teaching paradigm and cross-campus delivery, creates unique teaching and learning challenges.

To ensure equitable learning experiences and to enable successful learning outcomes to be achieved by all first year students, the issue of cross-campus management of first year PBL engineering courses becomes critically important.

\section{EDUCATIONAL PRACTICES}

\section{Educational Philosophy}

\section{a) Particular Challenges for Project Based Learning}

In 1994, Central Queensland University introduced cooperative education into its professional engineering program followed by Project Based Learning (PBL) in 1998. Since then the program has been developed to incorporate a unique combination of PBL, co-operative education and professional practice. Interested readers should refer to [1], [2], [3] and [4] for further discussion.

Course delivery across campuses provides challenges regardless of the teaching paradigm being employed. However the PBL paradigm provides some unique challenges due to its

October 28 - 31, 2006, San Diego, CA 
Session M1E

underlying philosophy. The PBL paradigm stresses learnercentric rather than teacher-centric education. It is therefore inconsistent to expect that the experience of each student will be the same. All that is required is that the outcomes are the same. The problem drives the student's learning with the teacher's role being as a 'facilitator' who guides the students by modeling the investigative process; [5], [6]. Students operate in a team environment and are expected to take greater responsibility for their learning. The aim of PBL is to encourage the student to become an independent learner with the capability and willingness to be a problem-solver and decision-maker in unfamiliar situations; [7], [8], [9]. The student develops the ability to acquire relevant information and apply it to the task at hand. This capacity to adapt to change also reinforces the need for life-long learning.

Because the course Engineering Skills I is in the first term of the students' first year of study and the PBL format is new for most students, the authors consider that a 'scheduled' form of PBL is appropriate to accustom learners to the novel paradigm. In 'true' PBL students would drive structure more than is currently the case. As a student progresses through the first year of study, there is a development towards 'real', less controlled, PBL and a resultant progression in the student's ability to drive their own learning. In addition to this, the authors believe that there is a need to structure the way in which PBL is presented (to some extent) in order to maintain quality and equity across campuses.

Part of the presentation of the course is a lecture given each week that is sent to all campuses via video-conferencing facilities. The lecture relates directly to the skills that are required for the project currently being undertaken. Students are encouraged to take an active role and interact with the other campuses by having them carry out activities throughout the session and provide feedback to the entire student cohort. These link-ups therefore provide an opportunity for students become more technologically savvy and also to feel that they are part of the larger student group.

Throughout the year, guest lectures are provided by a broad range of people from industrial, environmental, indigenous and political groups. These lectures, also delivered via the video-conferencing facilities, may originate from any one of the three campuses. A major benefit of this series of guest lectures is that the students are exposed not only to a range of political, cultural and environmental viewpoints but also opinions and beliefs that vary due to geographical location. Students are expected to critically assess their learning, including these lectures, in a reflective journal that forms part of their assessment for the course.

The workshops for the course are run individually at each campus. Identical teaching resources are provided to every member of the teaching team via email on a weekly basis. However despite the fact that the same resources are provided to all, each teaching staff member will bring their own set of skills, attitudes and prejudices to the workshops. The teaching staff member must carefully balance the need to guide the learning against the urge to hijack the agenda. The teaching staff member must also guard against being used as an easy resource. Each facilitator should direct students to potentially appropriate resources rather than allowing themself to be overused as a resource. It is important to ensure that students are directed rather than given 'easy answers' also assists in maintaining equity across the different campuses.

\section{b) Maths/Physics}

These courses are neither co-ordinated nor taught by the team of teaching staff members engaged in Engineering Skills I and II. We make comment on these courses briefly in order to highlight the overall first year experience however we do not provide extensive detail as the focus of this paper is on the Engineering Skills I and II PBL courses.

The mathematics and physics courses are conducted in traditional lecture/tutorial mode. These courses are presented face-to-face on each campus. There is currently no interaction between students from different campuses for these courses. Staff teaching these courses stay in regular contact throughout the term through email and telephone and assessment is moderated across campuses.

\section{Learning Experiences: Staff Professional Experience, Community and Professional Engagement}

The professional experience of each facilitating staff member differs considerably in terms of both discipline and background. This approach correlates well with [10] definition of scholarship while "...scholarship means engaging in original research, it also means stepping back from one's investigation, looking for connections, building bridges between theory and practice, and communicating one's knowledge effectively to students".

\section{Curriculum for First Year PBL courses}

In first year, the PBL paradigm is utilised in the courses Engineering Skills I and Engineering Skills II. In each of these courses, students are assigned a series of projects. Whilst the learning is student-centred, resource workshops and lectures are staged to support successful project completion, and to ensure a structured learning environment. This provides the students with the necessary enabling skills to complete projects and achieve all course learning outcomes.

In Term 1, the projects are 'contrived' and are designed specifically to enable the attainment of learning outcomes for the course. Projects include topics such as "Design and Build", "History of Technology" and "Modelling and Simulation".

In Term 2, two major projects are assigned to student teams. Both projects are 'real world' where local industry and community groups from Rockhampton, Mackay and Gladstone provide the topics. The students must liaise with their industry client to ensure successful project completion. Teaching staff monitor project progress from an academic perspective, and may assist with basic technical content. The majority of technical content is both specified and facilitated 
by the project client. Some past clients have included the Australian Department of Defence, Queensland Department of Main Roads, Queensland Alumina Limited, various local schools and Government authorities.

\section{ENABLING AND MANAGING INTERACTIONS}

The basic inter-personal interactions that occur with crosscampus management of courses may be defined as teaching staff-to-teaching staff, teaching staff-to-students and studentsto-students. These interactions range from simple to complex and may be enabled by methods ranging from face-to-face contact, through to utilising complex communication technologies. There are also occasions during a year where all teaching staff and all students are brought together for specific activities, as a complete group.

\section{Complete Student/Teaching Staff Group Interactions}

\section{a) The first Face-to-Face Interaction Between Students and Teaching Staff}

At the commencement of each academic year, students and teaching staff from all campuses attend Rockhampton campus for a one day series of activities and workshops. This is designed to enable students and teaching staff to participate in educational and social interactions to initiate the student learning and introduction to Project Based Learning (PBL). Students also commence the process of building a working relationship between peers from their own campus (campus cohort) and peers from other campuses, between themselves (course cohort) and the facilitator on their campus, and between themselves and the teaching staff from other campuses. This is enabled through the provision of structured educational and team building physical exercises (eg. design, build and test activity, and rock climbing). During this period students also interact with other academic teaching staff that may teach them in their first year or in subsequent years. During this interaction students are also briefed on Faculty and course specific processes and expectations.

\section{b) Ongoing Video-conferencing}

Defacto face to face communication between students and teaching staff across all campuses takes place on a weekly basis for Engineering Skills I and II lectures via video conferencing. As an educational tool, video conferencing allows the Engineering Skills lectures to be fully interactive with equal participation in lectures between students and teaching staff from all three campuses.

\section{c) The Second Face to Face Interaction Between Students and Teaching Staff}

Direct face to face interaction between students and teaching staff also occurs in the second term of the first year when the entire first year engineering cohort meets at the Rockhampton campus (as this is the central point) to take part in a one day interactive sustainability workshop. The sustainability workshop requires that students form inter-campus groups to simulate a small city and explore sustainability issues as they relate to society [11].

\section{Staff-to-Staff Interactions}

\section{a) Face-to-Face}

The teaching team critiques the way in which courses are facilitated at face-to-face meetings both before and after each teaching term as well as maintaining regular email and phone contact throughout the terms. The face-to-face meetings are used both as an opportunity for reflection on the previous term and planning for the term ahead. For the term just ended, the team moderates student portfolios and discusses the activities that worked well and those that could be improved. This reflection is then later used as a basis for planning the conduction of the course in the following year. For the term about to begin, the team finalises the planning that began the previous year and focuses on the details of conduction of learning activities.

The teaching team has found these sessions to be an extremely useful tool in the continuous improvement of the courses, as well as giving each team individual constructive feedback on ways to develop their own facilitation skills.

The members of the teaching team are also learners. As such we actively and in a credible way, not arbitrarily nor falsely, model the same behaviors that we ask the students to engage in, thus ensuring that our actions correlate with the expectations of behaviors we are espousing such as team building, communication, reflective practice and peer mentoring. Across the campuses, we as colleagues/peers, through our interactions, facilitate and support each other in the reflection process and where necessary provide peer mentoring. Furthermore as [12] highlights the common goal of all of this "is to develop a heightened awareness of one's own pedagogy, to be aware of the instructional decisions one is making and to realize that the choices that are made impact the learning in the classroom".

\section{b) Video-conferencing, Telephone and Email}

From year to year, teaching staff may move in or out of the teaching team. Thus in any year, there are some members of the team who are familiar with the course and some for whom it is a new experience. It is therefore essential that all members of the team are kept informed of activities from week to week, and also that all members of the team are able to contact other members if they are unsure about a particular activity. The face-to-face meetings before and after term are extremely valuable for 'breaking the ice' for new members of the team. However inevitably during the term, teaching team members have questions, particularly in relation to issues they feel may impact on students' perceptions of fairness across campuses. 
This on-going contact between members of the teaching team generally occurs by telephone and email. A Member of the teaching team will generally email the entire teaching team if they have a question that they feel will impact on everyone. However, teaching team members will also often have built up a rapport to the extent that they will telephone another team member to discuss problems that may be particular to their students in order to get advice on appropriate strategies. It is recognised that all facilitators are different and that each member of the teaching team will utilise their own individual approach to facilitating their campus cohort. However by maintaining regular contact and developing a genuine team approach, both students and teaching staff achieve positive outcomes. Bi-weekly teaching team teleconferences are conducted to effectively facilitate the reflective and continuous improvement processes.

\section{c) Course Coordination, Delivery Structure and Reflective Practice}

Course coordination can be performed from any campus while teaching staff provide face-to-face services at all campuses. teaching staff various engineering discipline backgrounds in civil, electrical and mechanical engineering. The first year courses are non-discipline specific with a focus on the attainment of broad enabling technical skills and generic professional practice skills. The development of student skills such as communication, teamwork, research and independent learning, also enables students to gain some basic technical engineering knowledge to assist with the 'higher level' completion of first year projects.

The course coordinator provides weekly advice, in advance, of the learning materials required to conduct lectures and workshops for the following week, This is achieved by using email with file attachments. Teaching staff from all campuses share the presentation of lectures using videoconferencing and these are conducted as a collegial activity with multiple interactions from all staff. Individual campus teaching staff facilitate the workshops at their respective campus. Teaching staff meet at the end of each term for the purposes of assessment moderation and reflection for course improvement.

\section{Staff-to-Student Interactions}

\section{a) Face-to-Face}

The course cohort and teaching staff associated with first year engineering, attend an induction week (Week 1, Term 1) and a sustainability workshop (Week 7, Term 2) at Rockhampton Campus.

The campus cohort activities involve the conduction of workshops which are learning resource activities conducted in face-to-face mode. Weekly lecture presentations are shared across campuses utilising video-conferencing for delivery. All campus cohorts have access to a designated 'First Year Engineering Project Studio' which is accessible to them 24 hours a day. This provides a venue where teams can meet and work on their projects at any time that fits in with their other commitments.

\section{b) Video-conferencing, Email and Web-based Learning Management System}

Cross-campus teaching of the course cohort is accomplished by utilising video-conferencing facilities that allow combined video and audio interaction between CQU campuses. Students are also increasingly making use of communication technologies for their teamwork interactions, with some teams using web-based meetings from their home workstations to discuss progress on team projects.

The delivery of learning materials and resources is accomplished by utilising a variety of methods. Lectures are delivered across campuses using a video-conferencing system that enables synchronous interactions between all campuses., Workshops are conducted in face-to-face mode delivered by individual staff at the respective campuses. On-line provision of learning materials is enabled through the use of a webbased learning management system called Blackboard [13]. Students can access resources such as course profiles, lecture notes, workshop materials, project scopes, assessment item commentaries, and relevant web links. Blackboard also provides students with email access to others in the cohort and a discussion board facility.

Each campus has teaching staff for all first-year courses on-site. Students have face-to-face contact with their campus staff several times a week. Face-to-face contact with teaching staff and students from other campuses occurs twice a year.

The video-conferencing facilities available at CQU have been in regular use for several years. In many courses, these facilities are used in traditional lecture mode with the communication largely being from lecturer to student. However, these facilities are also used in more innovative ways in some courses, with students being encouraged to interact freely with staff and students at other geographical locations.

\section{Student-to-Student Interactions}

\section{a) Face-to-Face}

Face to face student interaction during the design/build workshop, the weekly video-conference lecture, and the sustainability workshop in Rockhampton, form an important part of the first year curriculum. In addition to the curriculum requirements, this face to face interaction allows students from the Mackay and Gladstone campuses to become familiar with the Rockhampton campus layout and Rockhampton Engineering Faculty staff. This face to face interaction also allows students from all campuses to develop a degree of camaraderie before studying together at the Rockhampton campus in subsequent years. Research conducted by [14] has shown that students which are comfortable and familiar with classmates stand a better chance of success in tertiary study. 
Session M1E

\section{SUCCESSFUL CROSS-CAMPUS MANAGEMENT}

\section{Quality Assurance Processes and Success Indicators}

\section{a) Teaching and Learning Evaluation}

The teaching and learning quality processes at CQU include course and teaching evaluations which are completed by the students. These evaluations are student assessment of the courses in which they are enrolled, and assessment of the individual staff facilitating the courses. All student evaluations provide valuable feedback for continuous improvement of the courses, and as well they may be used to gauge students' satisfaction for a particular course. Table IV shows 2004 course evaluation data for Engineering Skills I and Engineering Skills II as supplied by CQU Division of Teaching and Learning Services. The responses are to a set of 20 standards questions requiring an assessment based on the following scale:

NA - not applicable

$\mathrm{SD}$ - strongly disagree $($ score $=1)$

$\mathrm{D}$ - disagree $($ score $=2)$

$\mathrm{N}-$ neutral $($ score $=3)$

$\mathrm{A}-$ agree $($ score $=4)$

$\mathrm{SA}-$ strongly agree $($ score $=5)$

Table II: Course evaluation data for Engineering Skills I and II - 2004 reported as an average score and equivalent percentage.

\begin{tabular}{|l|c|c|}
\hline & $\begin{array}{c}\text { Average } \\
\text { score } \\
(1-5)\end{array}$ & $\begin{array}{c}\text { Equivalent } \\
\text { percentage }\end{array}$ \\
\hline Engineering Skills I & 3.94 & 78.8 \\
\hline Engineering Skills II & 3.88 & 77.6 \\
\hline
\end{tabular}

It can be seen that based on the average of responses to the standard questions presented to students in the course evaluation questionnaires, students have a generally high level of satisfaction with the first year PBL courses, which are managed and delivered across three campuses. Data observed from other years also shows a similar level of course satisfaction.

\section{b) Undergraduate Attrition Rates}

Attrition rates are one of a range of indicators of outcomes that can be used to measure the performance of an educational institution. Attrition rates provide a measure of the proportion of students who 'drop out' of a course. Table II shows attrition data for CQU published by [14 ].

TABLE III: Rates of student attrition for CQU first year students in all undergraduate programs.

\begin{tabular}{|l|l|l|l|l|l|l|l|}
\hline Year & 1995 & 1996 & 1997 & 1998 & 1999 & 2000 & 2002 \\
\hline $\begin{array}{l}\text { Attrition } \\
\text { rate (\%) }\end{array}$ & 30.2 & 31.2 & 32.4 & 33.2 & 29.1 & 25.3 & 27.8 \\
\hline
\end{tabular}

TABLE IV: Withdrawal rates for Engineering Skills I and II.

\begin{tabular}{|l|c|c|c|}
\hline & $\mathbf{2 0 0 3}$ & $\mathbf{2 0 0 4}$ & $\mathbf{2 0 0 5}$ \\
\hline Eng Skills I & 7.1 & 12.8 & 6.1 \\
\hline Eng Skills II & 10.5 & 17.6 & 10.5 \\
\hline Total* & 16.5 & 28.2 & 15.9 \\
\hline
\end{tabular}

*Annual totals have been adjusted to account for the compounding effect of considering 'follow-on' courses in any one year to give an equivalent annual withdrawal rate.

Source of data: [15].

Even though the definitions of attrition and withdrawal are not necessarily the same it can be observed form Tables II and III that Engineering Skills I and II exhibits average withdrawal rates which are well below the institutional attrition rates.

\section{c) Staff Feedback as a Qualitative Indicator}

Historically staff morale in the teaching team has been extremely high. Staff have nominated that the high level of support from colleagues and the sense that they are supported and "not on their own" when operating from any individual campus, has provided an enviable working environment. The group operates well as a "teaching team" and the formal and informal support network is cited as a key facet enabling such successful interactions between staff-staff and staff-students, and faculty-community.

\section{d) Quality of Student Learning Experiences}

A major challenge within the first year courses is to ensure that students from all campuses are exposed to, and have the opportunity to engage in, equitable learning experiences. The non-PBL curriculum for maths and physics is clearly defined in terms of technically focussed learning outcomes and assessment items, while in Engineering Skills, though the PBL curriculum is well defined, there is much more scope for the possibility of facilitator influence and bias.

The consistency of the student's learning experience is managed by the highly developed collegial relationships (a true espirit de corps) between the facilitators and arises from the multiple and frequent communication channels. Also the quality of the learning experience is preserved because there is an agreed teaching practice, a consensus on the direction and focus of the activities supported by regular communication and planning prior to and during the term of offering. Through the cross-campus interactions of the video-conferencing sessions facilitators gain a clear indicator of student's thinking. Therefore as a collective, the group of facilitators and students are able to critique and provide synchronous feedback and guidance. In this way moderation of behaviours, knowledge, misconceptions and their participation provides 
continuous improvement opportunities for all students thereby enabling equitable learning experiences.

Even though each facilitator manages groups from their individual campus locations, the end of term moderation processes, which involves all of the facilitators, regularly demonstrates that there is parity of assessment outcomes between the campus cohorts.

This demonstrates the effectiveness of the quality assurance processes that is being achieved through the consistency of approach, the standard of work agreed upon and the attainment of the stated learning outcomes.

\section{CONCLUSIONS}

The reasons for introducing a PBL pedagogy as a tool in the education of engineering students are clear. Benefits include higher levels of communication skills, professional skills, and increased problem solving skills resulting from the deeper levels of learning provided by PBL. The challenge to educators employing PBL in a multi-campus environment shall remain one of standardisation and quality control.

The quality and effectiveness of cross-campus management of first year engineering courses can be assured by effective staff communication (both synchronous and non-synchronous), promoting a common negotiated understanding of pedagogy, ongoing course and teaching evaluation, establishing and maintaining effective collegial relationships and the continual moderation of course learning activities, outcomes and assessment items.

Whilst "success" is a subjective measure of performance we observe that qualitative evidence indicates that the crosscampus management of first year PBL engineering courses at CQU are performing well. Quantitative evidence such as student evaluation of courses and attrition/withdrawal rates also supports that successful strategies for cross-management are being achieved.

\section{REFERENCES}

[1] Toft, Y., P. Howard, and D. Jorgensen. "Toward a sustainable future an alternate model for teaching undergraduate ergonomic and engineering courses." Ergonomics for life: at work, home, and leisure, Proceedings of the Ergonomics Society of Australia Inc. 36th Annual Conference, October 8-11, 2000.

[2] Smith, R., D. Jorgensen, P. Howard, I. Devenish and P. Keleher. "Project Based Learning: Challenging Traditional Learning Paradigms". Smart State - Science Conference, Brisbane, 24-25 October, 2002.

[3] Howard, P., Jorgensen, D. \& Nouwens F., 2003, Enhancing Learning and Employability of Engineering Graduates at Central Queensland University: A Ten-Year Project. Business/Higher Education Round Table (BHERT) News, Developing Generic Skills: Examples of Best Practice Issue 16, April 2003.

[4] Howard, P., and D. Jorgensen. "Development of a Professional Bachelor of Engineering Program - A Ten Year Project and Project Based learning and Professional Practice - Enhancing Co-operative Education.' The $14^{\text {th }}$ World Conference on Cooperative Education, including the $3^{\text {rd }}$ International Conference on Practice Orientated Education, June 14-17, Northeastern University, Boston, Massachusetts, 2005.
[5] Barrows, H., Problem-based Learning Applied to Medical Education. Springfield, Illinois: Southern Illinois University School of Medicine, 2000 .

[6] Charlin, B., Mann, K. and Hansen, P., The many faces of problem-based learning: a framework for understanding and comparison'. Medical Teacher 20, 1998, pp323-330.

[7] Engel, J., Not just a method but a way of learning. In D. Boud and G. Feletti (Eds.), The Challenge of Problem-Based Learning, London: Kogan Page. 1991, pp. 21-31.

[8] Albanese, M. A., and Mitchell, S., Problem-based Learning: A review of literature on its outcomes and implementation issues. Academic Medicine 68, 1993, pp52-81.

[9] Ryan, G. L., and C.N. Quinn. "Cognitive apprenticeship and problem based learning." In Reflections on Problem Based Learning eds. S. E. Chen, R. Cowdroy, A. Kingsland and M. Ostwald, Sydney: Australian Problem Based Learning Network, 1994, pp15-33.

[10] Boyer, E.L., 1990, Scholarship reconsidered: Priorities of the Professoriate, Special Report, The Carnegie Foundation for the Advancement of Teaching.

[11] Martin, F., Keleher, P., Jorgensen, D. Steedman, M., Smith, K,. Workshopping a Sustainability Scenario with First Year Engineering Students in a Problem Based Learning Environment: Exploring and Appreciating Complexities of Attaining Sustainable Systems, Paper presented at the Second International Conference on Environmental, Cultural, Economic and Social Sustainability, Hanoi, Vietnam, 9-12 January 2006.

[12] Kilpatrick, C ., Hart, L., Najee-ullah, D., Mitchem, P., Reflective Teaching Practice by University Faculty: Rationale and Case Study in Computer Science, n.d.,

URL: http://fie.engrng.pitt.edu/fie97/papers/1258.pdf Accessed $18^{\text {th }}$ March 2006.

[13] BLS - Blackboard Learning System: Student Manual, 2002 URL: http://www.clt.odu.edu/BB/assets/pdf/Blackboard 6_Student_Manual.pdf Accessed $1 \overline{9}^{\text {th }}$ March 2006

[14] Jardine, A. and Krause, K., Once they arrive how do we keep them? Student Persistence and Implications for the retention of non-traditional students, Paper presented at the 2005 enhancing Student Support Conference, Ourumbah, 11April 2005,

URL:http://www.ccc.newcastle.edu.au/stuentsupport/2005 conference/papers. $\underline{\mathrm{htm}}$

[15] CQU enrolment database, 1995-2005.

\section{$36^{\text {th }}$ ASEE/IEEE Frontiers in Education Conference

